Revista de Ciencias Sociales - Número 66 (2015) - Páginas 165-185

Problemas bioéticos de la donación de órganos en la nueva ley chilena

\title{
PROBLEMAS BIOÉTICOS DE LA DONACIÓN DE ÓRGANOS EN LA NUEVA LEY CHILENA
}

\author{
BIOETHICAL PROBLEMS OF ORGAN DONATION \\ IN THE NEW LAW CHILEAN
}

\author{
MARÍA DEL PILAR MERINO SANTANDER* \\ Universidad de Valparaíso (Chile) \\ mariadelpilar.merino.s@gmail.com \\ MACK URTUBIA ROJAS \\ Universidad de Valparaíso \\ mack.urtubia.r@gmail.com
}

\section{Resumen}

La ley 20.673 de 2013 es la más reciente modificación a la ley de donación de órganos, y supone no sólo consolidar el sistema de consentimiento presunto, introducido en la anterior modificación legal, sino además incorpora el principio de reciprocidad, a propósito del cual surgen interesantes preguntas de fuerte contenido ético ¿Es justo reemplazar el criterio de la "necesidad médica” por el de la reciprocidad? Las magras tasas de donación han llevado a algunos autores a señalar que el modelo de donación basado en el altruismo ha alcanzado su límite y a vislumbrar, entonces, nuevas perspectivas en la materia.

\footnotetext{
* Egresados de la Facultad de Derecho y Ciencias Sociales, Universidad de Valparaíso (Chile). Artículo recibido el 27 de marzo de 2015 y aceptado el 5 de mayo de 2015.
}

Revista de Ciencias Sociales - Número 66 (2015) - Universidad de Valparáíso - ISSN 0716-7725-Valparaíso, Chile 


\title{
Palabras clave
}

Donación de órganos, reciprocidad, confiscación.

\begin{abstract}
The most recent amendment to the organ donation law (20.673) consolidates the presumed consent system and incorporates the reciprocity rule. This arise important ethical question: is it fair to replace the necessity rule for a reciprocity rule? Low donation rates indicate that the current donation model, based on altruism, has reached its limit and we need to consider the possibilities that a new model, based on strong incentives for donation, provides.
\end{abstract}

\section{Keywords}

Organ donation, reciprocity, confiscation.

\section{Introducción}

El desarrollo de la medicina en materia de donación de órganos ha posibilitado salvar miles de vidas humanas pues el escenario es cada vez más auspicioso al reducirse significativamente las tasas de rechazo y aumentar el tiempo y la calidad de sobrevida. Si bien la técnica del trasplante de órganos data de principios del siglo XX, fue recién en los años 60 cuando, en la praxis, se evidencia una mejora significativa con los procedimientos de inmunosupresión y la realización de los primeros trasplantes de riñón y corazón que se practicaron en Chile en la misma década, siendo nuestro país uno de los pioneros a nivel mundial ${ }^{1}$.

La primera regulación legal sistemática en la materia fue la ley 19.451 de 1996 sobre trasplante y donación de órganos la que, al lograr un tímido aumento de la donación, propició dos sucesivas modificaciones. La primera, la Ley 20.413 conocida como "ley de donante universal”, que determinó el tránsito entre el sistema de

1. El primer trasplante de corazón en Chile, se realizó en 1968, siendo uno de los tres primeros del mundo. Véase en: http://www.trasplante.cl/nuestracoporacion/quienes-somos/historia

Facultad de Derecho y Ciencias Sociales - Universidad de Valparaíso - Chile 
"consentimiento expreso" (o informado) al de "consentimiento presunto ${ }^{\prime 2-3}$. Luego, la Ley 20.673 pretendió enfrentar los errores de la reciente normativa reduciendo las posibilidades de manifestar la voluntad de no donar a sólo una: que el potencial donante presente una documentación fidedigna, otorgada ante notario público, en la que conste que en vida manifestó su voluntad de no donar.

De este modo la legislación vigente, siguiendo el modelo de países como España ${ }^{4}$, consagra el sistema de consentimiento presunto e introduce el principio de la reciprocidad que implica que, entre dos receptores en igualdad de condiciones médicas, se priorizará al que sea donante .

En lo que sigue se analizan los problemas bioéticos de la legislación vigente haciendo hincapié en dos grandes temas. Por un lado, las objeciones que el sistema de consentimiento presunto plantea desde el punto de vista moral y, por otro lado, las dudas en torno a la justicia o injusticia asociadas al principio de reciprocidad como criterio que reemplazaría el de sola necesidad médica. El sistema de donación de órganos basado en el altruismo ha alcanzado sus límites. Ante tal

2. GEVERS, Sjef, JANSSEN, Anke y FRIELE, Roland. "Consent systems for post mortem organ donation in Europe”. En: EuropeanJournal of HealthLaw, 11, No 2, 2004. Págs. 175-186.

3. Para efectos metodológicos utilizaremos los anglicismos opt-in y opt-out, para aludir a los dos sistemas actuales de donación de órganos. RODRÍGUEZARIA, David y CASADO, Antonio: "Controversias actuales sobre el consentimiento para la donación de órganos”. Ensayos sobre Bioética. Ediciones Universidad de Salamanca. I Edición. Octubre de 2009. Pág. 190.

4. El modelo español posee un sistema de consentimiento tácito, universal (vale decir, sin condición para recibir el órgano) y absoluto, de acuerdo con lo establecido en la Ley 30/1979 de 27 de octubre sobre extracción y trasplante de órganos, y en el Real Decreto 2070/1999 de 30 de diciembre por el que se regulan las actividades de obtención y utilización clínica de órganos humanos.

5. Chile se suma a Israel y Singapur, quienes han introducido la reciprocidad en sus leyes de donación de órganos. ZÚÑIGA-FAJURI, Alejandra. "Increasing organ donation by presumed consent and allocation priority: Chile". Bulletin of the World Health Organization, 2015; 93: pp. 199-202.

Revista de Ciencias Sociales - Número 66 (2015) - Universidad de Valparáíso - ISSN 0716-7725-Valparaíso, Chile 
escenario de escasez se requiere con urgencia ensayar mecanismos que permitan incorporar nuevos criterios para la adjudicación justa de recursos sanitarios escasos, como lo son los órganos para trasplante.

\section{La ley chilena en materia de donación de órganos}

Antes de adentrarnos en la legislación chilena es necesario revisar los sistemas de donación del derecho comparado. Ellos pueden agruparse básicamente en razón al carácter, la presencia de condición para ser receptor de un órgano y el ejercicio del consentimiento del donante. En razón al carácter, existen sistemas de "consentimiento expreso" u opting in, en el cual las personas deben manifestar expresamente en vida si desean o no convertirse en donantes al momento de su muerte; y sistemas de "consentimiento presunto" u opting out, en atención al cual, ante el silencio en vida, se presume por el sólo ministerio de la ley la condición de donante. En cuanto a la segunda clasificación, estaremos frente a un modelo "condicionado" si se exige una condición como requisito para ser receptor de un órgano. Si aquella no se pide, se tratará de un modelo "universal”. Finalmente, el sistema será “absoluto" si se considera sólo la voluntad del donante, sin valorar la voluntad de la familia. Si esta última tiene injerencia en la decisión, llegando incluso a modificarla, estaremos en presencia de un modelo "restringido"'.

La Ley 19.451 seguía un modelo de consentimiento expreso, universal y restringido, de modo que en caso de no haber manifestado la voluntad de ser donante en vida, la familia podía suplir el silencio en el orden de prelación que preceptuaba la ley. Es relevante destacar que el artículo $1^{\circ}$ consagra el fin exclusivamente terapéutico del trasplante y el carácter eminentemente gratuito de la donación de órganos; se determinan criterios respecto a qué se entiende por muerte (adhiriendo al concepto al que ha arribado gran parte de comunidad científica: la muerte cerebral) ${ }^{7}$ y se crea la Comisión Nacional del Trasplante.

6. RIVERA LÓPEZ, Eduardo. Ética y trasplante de órganos. Fondo de Cultura Económica, México, 2001, pp. 73 y ss.

7. Se cree que la generalización del uso del término "muerte cerebral” y su aceptación en la comunidad científica, deriva de una resolución de un comité

Facultad de Derecho y Ciencias Sociales - Universidad de Valparaíso - Chile 
El legislador de entonces, y tal como consta en la historia de la ley, tuvo un objetivo claro: además de crear una regulación especial que diera un tratamiento jurídico integrado a la donación y trasplante de órganos (más allá de las menciones en otros cuerpos legales, como el código sanitario) se ideó un marco legal que propiciara las donaciones de órganos por la vía de ofrecer al ciudadano "la posibilidad de contribuir libremente al bien común". Esta conminación del legislador a enfrentar las bajas cifras de donación por el camino del altruismo puro pretendía mostrar que la donación de órganos es un importante aporte social y colectivo a incentivar. Sin embargo, a pesar del sentido de "sencillez y afán de permanencia”" que le quisieron dar los autores de esta ley, el poco impacto social que tuvo desde su entrada en vigencia derivó en dos reformas. La primera de ellas se materializó en la ley 20.413, de 2010, que instaura la regla del “consentimiento presunto" y, además, el principio de confidencialidad de los datos tanto del donante como del receptor.

Sólo tres años después, y ante una impresionante caída en la tasa de donación ${ }^{10}$, se plantea una nueva modificación legal - Ley 20.673, 2013- que, luego de ratificar el sistema de consentimiento presunto, reduce drásticamente los mecanismos destinados a manifestar la voluntad de no ser donante. En efecto, se reemplazan las distintas instancias ante el Registro Civil (al momento de renovar el carnet de identidad o el de conducir) a sólo una: un documento fidedigno

ad hoc formado en la Universidad de Harvard en 1968, para dilucidar algunas interrogantes sobre el coma irreversible. BEECHER, Henry: "A Definition of Irreversible Coma. Report of the Ad Hoc Committee of the Harvard MedicalSchool to Examine the Definition of Brain Death”. En: JAMA, Vol. 205, 1968, págs. 337-340.

8. Historia de la Ley 19.451. Fundamentación de la Moción Parlamentaria. Pág. 557.

9. Historia de la Ley 19.451. Informe Comisión de Salud. Pág. 131.

10. Departamento de Evaluación de la Ley. Cámara de Diputados de Chile: Evaluación Ley 20.413. Disponible en: http://www.evaluaciondelaley.cl/ foro_ciudadano/site/artic/20121210/asocfile/20121210165152/informe_ final_evaluaci_n_20413.pdf

Revista de Ciencias Sociales - Número 66 (2015) - Universidad de Valparáíso - ISSN 0716-7725-Valparaíso, Chile 
específico otorgado ante notario público. Junto con ello, se introdujo el principio de reciprocidad como mecanismo para decidir sobre la adjudicación de un órgano, con lo cual el modelo pasa de ser universal a tener el carácter de "condicionado", puesto que aquel que manifestó la voluntad en vida de no ser donante, queda en una escala prioritaria inferior a quien no lo hizo.

\section{El origen de la regla de consentimiento presunto (opting out)}

El modelo español de donación de órganos se erige como el más exitoso del mundo. Según datos entregados por la Organización Nacional de Trasplantes de España (ONT), los más recientes datos lo consolidan por $23^{\circ}$ año consecutivo como el líder mundial en la materia: en 2013 se realizaron 4.279 operaciones de 1.655 donantes, lo que supone una tasa de 35,3 donantes por cada millón de personas ${ }^{11}$ ¿Cuál es la razón de su éxito? La regulación legal es, sin duda, un factor importante y así lo demuestran diversos estudios que han analizado el impacto del consentimiento presunto en el aumento de las tasas de donación en los países que lo han instaurado. Si bien es difícil determinar la relevancia relativa de la legislación en el aumento de las donaciones, lo cierto es que la adopción del sistema coincidió con significativos aumentos de las tasas de donación en algunos países. Es así como Austria aumentó de 4,6 donantes por millón de personas (pmp), a 27,2 pmp en un periodo de 5 años. Situación similar ocurrió con Bélgica y Singapur, que aumentaron las donaciones de riñones de 10,9 a 41,3 pmp y de 4,7 a 31,3 pmp, respectivamente, en un periodo de 3 años $^{12}$.

Ahora, ello no significa que el consentimiento presunto per se conduzca a un aumento en las tasas de donación ${ }^{13}$. Es así como se explicaría que en Brasil, por ejemplo, la promulgación de una ley que

11. Véase en: www.ont.es

12. RITHALIA, MCDAID, SUEKARRAN, MYERS, SOWDEN: "A systematic review of presumed consent systems for deceased organ donation". En: Health Technology Assessment, Vol. 13: No 26, 2009. Pág. 36.

13. RITHALIA et al: Ob. Cit. Pág. 39.

Facultad de Derecho y Ciencias Sociales - Universidad de Valparaíso - Chile 
instauraba el sistema de consentimiento presunto haya tenido que ser reemplazada luego que los ciudadanos acudieran masivamente a inscribirse a los registros para expresar su rechazo. Muchos brasileros creyeron que no se les trataría como pacientes en caso de encontrarse gravemente enfermos, sino que sólo como potenciales donantes de órganos. Incluso se adujo la posibilidad de que el cuerpo médico provocara su muerte para extraerles los órganos ${ }^{14}$. Esta reacción de "pánico" social se produjo también, según veremos, en Chile.

La evidencia muestra que, aunque importante, el factor legislación no es determinante en el éxito de un modelo de trasplante y donación de órganos. Aunque es fundamental la disponibilidad de donantes, también lo es la inversión del Estado en infraestructura hospitalaria y en personal especializado para la procuración de órganos. El éxito del modelo español se consolidó sumando a la regla del consentimiento presunto, un trabajo intenso de mejora en la infraestructura física y humana necesaria para aprovechar al máximo las donaciones que se reciben ${ }^{15}$.

\section{1. ¿De quién son los órganos post mortem?}

Es pertinente abordar ahora la titularidad de los órganos post mortem a propósito del consentimiento presunto. ¿Son los órganos propiedad absoluta de las personas, forman parte del dominio público o se trata de una propiedad limitada o restringida? Como se dijo, la actual normativa prescribe que de no manifestar en vida la voluntad de no ser donante, se presumirá de derecho que la persona lo es. Pocos discuten que las personas tienen derecho a decidir sobre el destino de su cadáver de modo que, sobre esa base, el legislador prevé la posibilidad de manifestar la voluntad de no ser donante de órganos. Por ello, expresar esta intención no requiere ser fundada, pudiendo atender a motivos

14. RODRÍGUEZ-ARIAS, David y CASADO, Antonio: "El consentimiento para la donación de órganos: tipología". Ensayos sobre Bioética. Ediciones Universidad de Salamanca, I Edición, 2009. Pág. 206.

15. RITHALIA, Amber, et al: Ob. Cit. Pág. 36.

Revista de Ciencias Sociales - Número 66 (2015) - Universidad de Valparáíso - ISSN 0716-7725-Valparaíso, Chile 
religiosos, morales, sociales o de cualquier otro tipo. El sistema de consentimiento presunto trata de hacer justicia a las obligaciones morales de solidaridad con enfermos graves ${ }^{16}$.

Por cierto que incluso en los sistemas de donación absolutos, en los que por definición la decisión expresada en vida debiera primar sin posibilidad de ser modificada por la familia una vez fallecido, la opinión de los familiares sigue siendo preponderante. En un estudio comparativo sobre los sistemas de consentimiento para la donación post mortem en Europa, analizando a 10 países, se llegó a la conclusión de que los sistemas puros opt-in y opt-out son una simplificación que no tiene en cuenta los matices con los que estos sistemas funcionan en la práctica $^{17}$. La participación de los familiares pone en jaque la idea de que los órganos son de propiedad absoluta de las personas en la medida en que no hay mecanismos que puedan hacer efectiva su voluntad una vez muerta.

Por ello, ante el grave problema de escases de órganos, hay quienes han planteado la necesidad de introducir el modelo de la confiscación. ¿Por qué razón debemos respetar los deseos póstumos relativos a nuestro cuerpo una vez muertos, y por qué razón debiéramos respetar la decisión de no donar de una persona que se benefició de la solidaridad ajena? Imaginemos, invita De Lora, que una persona que es trasplantada con un órgano manifiesta su voluntad en vida de no ser donante. No parece haber razón moral que nos obligue a aceptar una voluntad semejante. Probablemente la gran mayoría considerará intolerable que el Estado ampare aquella forma extrema de egoísmo ${ }^{18}$.

16. GEVERS, Sjef, JANSSEN, Anke y FRIELE, Roland: “Consent systems for post mortem organ donation in Europe". En: European Journal of Health Law, 11, 2004, No 2. Pág. 178.

17. El estudio abarcó el análisis a Austria, Bélgica, Francia, Alemania, Italia, Países Bajos, España, Suecia, Suiza y Reino Unido. Véase en: Gevers, Sjef, Janssen, Anke y Friele, Roland: Ob. Cit. Págs. 175-186.

18. DE LORA, Pablo: "El trasplante de órganos y el caso del tranvía. ¿ por qué no confiscamos los órganos del cadáver?”. En: Jueces para la democracia, $\mathrm{N}^{\circ} 75$, 2012, pág. 14.

Facultad de Derecho y Ciencias Sociales - Universidad de Valparaíso - Chile 
El modelo altruista se sustenta en una idea de propiedad no absoluta sobre los órganos, lo que constituye un estadio intermedio entre la propiedad absoluta y el dominio público. Ello es lo que permite que los herederos puedan disponer de los órganos como si se tratase de cualquier otro tipo de propiedad. Sin embargo, admite De Lora, este razonamiento no responde una pregunta vital ¿Para qué querrían los familiares esos órganos que sólo tendrían utilidad si con ellos se le prolongara la vida a otro ser humano? La familia debiera simplemente soportar que se le extraiga el órgano a su familiar, de la misma forma en que soporta muchas restricciones que el derecho nos impone después de muertos (como por ejemplo, en materia de autopsia y enterramiento $)^{19}$. Cuando los objetivos sociales que se pretende alcanzar son lo suficientemente valiosos — como prolongar la vida de las personas necesitadas de un trasplante- el derecho debiera estar legitimado para restringir la libre disposición de bienes públicos, como lo son los órganos post mortem.

\subsection{Modelo de la Confiscación: los órganos como bienes públicos}

¿Es la regla del consentimiento presunto un mecanismo de confiscación? Cecchetto señala: "Aunque nadie pueda arrogarse legalmente la propiedad del cadáver, afectivamente sus deudos sentirán que les pertenece y allí radica — todavía - un valor que les atañe. Convertirlo en un bien público implica una confiscación por parte del Estado, una despropiación que necesita un consenso social para llevarse adelante" ${ }^{20}$. Pero el sistema de consentimiento presunto no es del todo de carácter confiscatorio en la medida en que siempre puede, tanto el titular en vida, como sus familiares, oponerse a la destinación inicial fijada en la ley por el Estado, por lo que sigue enmarcándose en el altruismo.

\footnotetext{
19. Ibídem, pág. 25.

20. CECCHETTO, Sergio. "La propiedad del cuerpo humano: consentimiento expreso y presunto en la donación de órganos". En Doctrina Promiscua; Ediciones Suárez, Mar del Plata, 2003. Pág. 63.
}

Revista de Ciencias Sociales - Número 66 (2015) - Universidad de Valparáíso - ISSN 0716-7725-Valparaíso, Chile 
Con todo ¿habría razones morales fuertes para apoyar de lleno una legislación de tipo confiscatoria? Cécil Fabre considera que las reglas de justicia distributiva, propias del liberalismo igualitario de Rawls, permiten extender la intervención estatal a la redistribución de órganos y tejidos. Puesto que tratándose de órganos de cadáver no estarían en juego, por razones obvias, ni la vida ni la integridad física de su titular, la confiscación de órganos sólo podría afectar los intereses póstumos del difunto, aunque esta idea pueda parecer absurda pues difícilmente un muerto puede tener intereses ${ }^{21}$. Luego, incluso si se adhiere a la idea de interés póstumo, éste no podría superponerse a la posibilidad de salvar vidas.

Como ya hemos indicado, no se respetan todos los intereses o deseos póstumos de las personas. Las normas de orden público no podrían ser inobservadas por razones religiosas, por ejemplo, pues no contarían con el peso suficiente para evitar su fuerza preceptiva. Fabre considera que una objeción de conciencia frente a la idea de confiscación -que según la línea argumentativa sostenida en este trabajo podría ser una carga y tener la categoría de norma de orden público- sólo podría ser atendible si dicha objeción resiste las concepciones críticas de otros y, a la vez, es inteligible tanto a quienes no obtendrán su órgano, como a aquellos que sí estarán bajo la obligación de darlo ${ }^{22}$.

Entendiendo que la persona ha dejado de existir como tal al momento de fallecer, carece de derechos individuales y pasan a primer plano los derechos sociales, y por tanto los deberes de justicia. En base a razonamientos como este, se erige toda la doctrina europea de la donación de órganos de cadáver. Atendiendo a ella es que países europeos tiendan a considerar a los órganos procedentes de cadáver como bien público, los cuáles deben maximizarse a favor de quienes puedan necesitarlos, y por tanto, se les considera como bien social y no individual ${ }^{23}$.

21. FABRE, Cécile: "Whose Body Is It Anyway: Justice and the integrity of the person?”. En: Oxford: Clarendon Press, 2006. Págs. 100-102.

22. Ibídem. Pág. 86.

23. MARTÍN, Antonio, MARTÍNEZ, José Manuel, LÓPEZ, Jorge: "La donación en España: un estudio sobre los aspectos psicosociales". En: Coordinación y trasplantes. El modelo español. Madrid, Grupo Aula Médica S.A. 1995. Pág. 105.

Facultad de Derecho y Ciencias Sociales - Universidad de Valparaíso - Chile 


\section{Principio de reciprocidad}

El modelo de confiscación no parece estar cerca de ser implantado en algún país, y por ahora, sólo es promovido por algunos autores que desde la academia lo abordan como una forma de enfrentar la escasez de órganos. Mientras aquello sucede, seguimos en el afán de analizar el modelo chileno, que a pesar de la reciente data de su configuración actual, bien podría ser considerado una alternativa exitosa a lo que ya conocemos.

La característica distintiva del modelo chileno actual, además del consentimiento presunto, es la adopción de un modelo condicionado a partir de la introducción de un criterio no médico a la asignación de órganos, como lo es el principio de reciprocidad. ¿Cómo funciona el sistema? Bajo la política de la reciprocidad quienes se comprometieran a donar, recibirán una ventaja significativa en la asignación de órganos si eventualmente necesitaran un trasplante ${ }^{24}$. La consagración de aquel principio en nuestra legislación, establece que en caso de que varias personas se encuentren en igualdad de condiciones para la recepción de un órgano, el hecho de no ser donante deberá tomarse en cuenta, quedando en una escala prioritaria inferior en relación a quien lo es ${ }^{25}$. La adopción de este principio no estuvo exenta de críticas en el proceso legislativo, ni en la comunidad médica y científica.

En Israel (segundo país en adoptar el principio luego de Singapur) la discusión fue particularmente ardua producto de la composición demográfica de dicho Estado, en el cual de los más de 8 millones de habitantes, el 75\% de la población profesa el judaísmo. La Ley Judía prohíbe la profanación del cuerpo, lo que ha sido interpretado por muchos en el sentido de que aquella religión prohíbe la donación de órganos, esto sumado a las cuestiones rabínicas que rodean el concepto de muerte cerebral. Como consecuencia de lo anterior, Israel

24. NADEL, Mark, NADEL, Caroline: “Using Reciprocity to Motivate Organ Donations". En: Yale Journal of Health Policy, Law, and Ethics. Vol. 5: Iss 1, Article 5, 2005. Pág. 314.

25. Artículo 2 bis, inciso final de la Ley 19.451 que establece normas sobre Trasplante y Donación de Órganos.

Revista de Ciencias Sociales - Número 66 (2015) - Universidad de Valparáíso - ISSN 0716-7725-Valparáiso, Chile 
figuraba con las más bajas tasas de donación que cualquier país desarrollado ${ }^{26}$. El periódico The New York Times, en un reciente artículo evidenció las dificultades que enfrenta el sistema de donación de órganos del Estado Judío, titulado: "Choque de Religión y Bioética dificulta la Donación de órganos en Israel”. Para entender algo más de las paradojas a propósito del binomio ética-religión, el Dr. Jacob Lavee, quien dirige el programa de trasplante de corazón en el Sheba Medical Center en Tel Hashomer en Israel, señaló que una actitud coincidente entre sus pacientes judíos ortodoxos era no estar dispuestos a donar, pero sin embargo, no mostrarían la misma reticencia si se tratara de recibir un órgano ${ }^{27}$. En aquel contexto, se implementó el principio de reciprocidad en Israel, lo que Lavee denominó como un paso entre el mero altruismo al "altruismo recíproco" 28.

En Chile si bien la discusión sobre el principio de reciprocidad no tuvo el cariz religioso, su propuesta fue aprobada sin terminar de convencer del todo a algunos parlamentarios ${ }^{29}$. En la discusión ya se hacía patente la dificultad de la concreción del principio de reciprocidad en la práctica, puesto que las listas de receptores de órganos se confeccionan en base a criterios médicos. Con todo, primó la idea de que la adopción de una norma con dicha característica "ayudaría a la promoción de la donación de órganos”30, lo que resulta urgente.

26. Israel cuenta con un sistema consentimiento expreso u opt in. $\mathrm{Al}$ año 2008 sólo el $10 \%$ de la población adulta estaba inscrita en el registro de donantes. Véase en: LEAVE, Jacob,ASHKENAZI, Tamar, GURMAN, Gabriel, STEINBERG, David: "A new law for allocation of donor organs in Israel". En: Lancet, Vol. 375, No 9720, 2010. Pág. 1.131.

27. LAVEE, Jacob. (2012, 16 de febrero). Entrevista The New York Times.

28. LAVEE, Jacob, ASHKENAZI, Tamar, GURMAN, Gabriel, STEINBERG, David. (2010). Ob. Cit. Págs. 1131-1133.

29. En la comisión de salud fue aprobada por 4 votos a favor, entre ellos el del H. Senador Mariano Ruiz-Esquide, quien durante la discusión se mostró en desacuerdo con incorporar el principio. Votó en contra el H. Senador Francisco Chahuán.

30. Intervención del Honorable Senador Guido Girardi. Historia de la Ley 20.673, pág. 98.

Facultad de Derecho y Ciencias Sociales - Universidad de Valparaíso - Chile 


\subsection{Respuesta a las principales críticas}

\section{a) "No genera más donaciones"}

Nadel y Nadel hacen mención a alguna de las principales críticas que se esbozan en relación al principio de reciprocidad. Entre ellas, que la adopción de dicho principio no produciría más donaciones. Aunque se trata de un recurso de reciente data - lo que dificulta un análisis cuantitativo acabado- no es difícil argumentar razones de utilidad e instrumentalidad, pues su aplicación obligará a las personas a una mayor reflexión acerca de la decisión de no donar en atención a sus consecuencias.

En palabras de Eduardo Rivera, existirían razones consecuencialistas para abrazar aquel principio, pues el temor de una persona a no recibir un órgano, salvo haya manifestado su voluntad expresa de donar (que en Chile equivale a no solicitar la inclusión en la lista de no donantes), se erige como un incentivo para hacerlo ${ }^{31}$. A modo de ejemplo, estudios preliminares sobre la eficacia de su implementación en Israel suponen un considerable apoyo público entre sus ciudadanos ${ }^{32}$, lo que se refleja en que desde su incorporación se ha experimentado un aumento récord en la firma de la tarjeta de donante, a la vez que se ha producido un alza significativa en el número real de trasplantes ${ }^{33}$.

31. RIVERA, Eduardo. Ob. Cit. Pág. 90.

32. Estudios previos a la implementación de la nueva normativa evidenciaban el apoyo de los israelíes a la incorporación de un principio de reciprocidad. En dos encuestas realizadas en Israel en 1999 y 2004 para conocer las actitudes de la población respecto de la donación de órganos, realizadas por el Centro Nacional de Trasplantes de Israel, el 55\% de los individuos en cada encuesta, indicó su voluntad de donar órganos a cambio de priorización en la asignación de los mismos. LAVEE, Jacob, ASHKENAZI, Tamar, GURMAN, Gabriel, STEINBERG, David. (2010). Ob. Cit. Pp. 1.131.

33. CRONIN, Antonia: "Points mean prizes: priority points, preferential status and directed organ donation in Israel”. En: Israel Journal of Health Policy Research, Vol. 3, 2014. Pág. 2.

Revista de Ciencias Sociales - Número 66 (2015) - Universidad de Valparáíso - ISSN 0716-7725-Valparaíso, Chile 


\section{b) "Amenazaría la pureza altruista"}

En la mayoría de los diferentes modelos de donación de órganos presentes en el derecho comparado se consideraron tres premisas a la hora de estructurar el sistema: primero, que el cuerpo humano no puede ser tasado en términos mercantiles, por tanto la donación tendría el carácter de gratuito; segundo, que la donación no representara ningún perjuicio para el donante y; tercero, que las personas altruistas donan pues son capaces de sentirse comprometidos con las necesidades de quienes necesitan de los órganos, lo que promueve la cohesión social ${ }^{34}$.

En Chile las premisas descritas han sido incorporadas a la legislación por la vía de invocar la necesidad de promover el altruismo y espíritu solidario como principal incentivo para aumentar las cifras de donación. Paradójicamente, la oposición en el debate legislativo de la ley a la adopción del principio de reciprocidad se centró en la idea de dar permanencia a la idea "pura" de altruismo, señalándose que "la exigencia de reciprocidad importa una represalia, inequidad y estigmatización, que va en sentido opuesto al consentimiento informado y contra el altruismo propio de las donaciones y de la necesidad de incentivar la donación como un hecho generoso y no como una acción que se realiza por temor" ${ }^{\prime 3}$. Pero lo cierto — como argumentan Lavee y otros (2010) es que una política prioritaria haría realidad una forma de altruismo recíproco que presume que la introducción de una condición como la descrita supone conminar a los ciudadanos a realizar una reflexión más acabada acerca de la donación, y a creer que una negativa a donar, conociendo las consecuencias que ello acarrea, obedecerá a razones serias y no a prejuicios o desinformación.

El altruismo recíproco (que desde la teoría económica se comprende como "acciones que confieren un beneficio a otros a cambio de un coste para quien las realiza, pero con la perspectiva de un beneficio recíproco suficiente para cubrir esos costos") ${ }^{36}$ bien puede ser el punto

34. CARDOSO, Cruz, CASAS, María de la Luz, RAMÍREZ, Hugo: “Los costos del altruismo en Donación de Órganos”. En: Cuadernos de Bioética, Vol. 21, No 2, 2010. Pág. 157.

35. Historia de la Ley 20.673, pág. 116.

36. Véase en: BOWLES, Samuel, et al: "Group Competition, Reproductive Leveling, and the Evolution of Human Altruism”. En: Science, Vol. 314, 2006.

Facultad de Derecho y Ciencias Sociales - Universidad de Valparaíso - Chile 
medio entre el egoísmo y la generosidad desinteresada, pues se condiciona un comportamiento beneficioso para otros si el coste de ayudar se ve compensado por la probabilidad de beneficiarse uno mismo. En biología evolutiva existen teorías de altruismo recíproco entre ciertas especies, por lo que este comportamiento ha sido observado tanto en animales como en humanos y parece ser una característica innata de supervivencia que aplica muy bien ante las demandas desesperadas de órganos para salvar vidas.

\section{c) "Sólo criterios médicos en la asignación de órganos"}

La tercera crítica recurrente ha sido que sólo deben primar criterios médicos a la hora de determinar quién será receptor de un órgano. En Chile, para realizar tal tarea, existe una base de datos donde están identificados todos los pacientes que esperan por un trasplante de órganos, junto con los datos necesarios para poder asignar un órgano disponible al receptor más adecuado. Dicha información se actualiza permanentemente con los datos que envían los centros de trasplantes y con los exámenes de los laboratorios de histocompatibilidad en razón a los requerimientos del órgano a trasplantar y de las características biológicas de cada paciente.

Según el Instituto de Salud Pública, los criterios para la confección de esta base de datos — conocida como "Listas de Espera"son la compatibilidad de grupo sanguíneo entre receptor y donante, la compatibilidad de los antígeno, compatibilidad de peso-talla y la urgencia médica. La importancia de cada factor varía según el órgano a trasplantar. Dichos factores o criterios son los que se consideran médicos, en tanto que el factor de reciprocidad es considerado un criterio no médico, que reviste un contenido ético que podría ejercer, según algunos, una influencia corruptora en la asignación de órganos ${ }^{37}$. Sin embargo, siguiendo a Nadel y Nadel, es difícil determinar cuándo estamos en presencia de un criterio médico a secas o cuando un criterio médico no plantea también cuestiones éticas. Por ejemplo, algunos

37. CAPRON, Alexander: "More blessed to give than to receive?". En: Transplantation Proceedings, Vol. 24, 1992. Págs. 2185-2187.

Revista de Ciencias Sociales - Número 66 (2015) - Universidad de Valparáíso - ISSN 0716-7725-Valparáiso, Chile 
podrían considerar al tiempo de permanencia en la lista de espera como un sustituto de la urgencia médica.

Charlesworth arguye que "un paciente puede tener la mejor posibilidad de sobrevivir a una enfermedad aguda; otro puede tener la mayor posibilidad de vivir más años; otro puede recibir mayor alivio de su sufrimiento, y otro podría obtener la mayor satisfacción. Los hechos médicos por sí solos no pueden decirnos cuál de estos pacientes se beneficiaría más de la diálisis o del transplante" 38 . Por ello, se busca no dejar al arbitrio de la moralidad individual decisiones tan trascendentes, intentando otorgarle al proceso de la donación y trasplante de órganos un carácter técnico. Sin embargo, la adopción de la reciprocidad no vulnera este objetivo pues, en la práctica, la probabilidad de que dos pacientes se encuentren en igualdad de condiciones, como establece la ley, es tan difícil que el criterio de la reciprocidad no tendría gran aplicación práctica en el hecho mismo del trasplante. Su objetivo, en cambio, es moderar el egoísmo y el desinterés en los más necesitados.

En las democracias modernas, la resolución de los dilemas morales asociados a la adjudicación de recursos escasos debe quedar entregada al órgano representativo por antonomasia: el parlamento. La adopción legal de este principio, como mecanismo para incentivar la donación de órganos en Chile, resulta más beneficiosa que perjudicial al sistema sanitario, según evidencian los datos de donación y trasplante posteriores a la entrada en vigencia de la ley ${ }^{39}$.

\subsection{Efectos de la adopción del principio}

En primer lugar, el principal efecto que produce un sistema condicionado con presencia del principio de reciprocidad es la mayor disponibilidad de órganos para salvar vidas. En segundo término, se

38. CHARLESWORTH, Max: La bioética en una sociedad liberal. Cambridge UniversityPress.Traducción de Mercedes González. 1996. Pág. 176.

39. ZÚNIGA-FAJURI, A.: "Increasing organ donation by presumed consent and allocation priority: Chile". Bulletin of the World Health Organization, 2015; 93: 199-202.

Facultad de Derecho y Ciencias Sociales - Universidad de Valparaíso - Chile 
estaría terminando con la odiosa situación que se presenta cuando un no donante recibe un órgano, promoviéndose de mejor manera nociones básicas de justicia en la línea propuesta por Rawls: "sólo los que están dispuestos a hacer justicia, tienen derecho a ella" ${ }^{40}$. Por último, la pertinencia de un modelo condicionado evita la existencia de los free raiders, aquellos individuos que no están dispuestos a donar sus órganos pero sí a recibir uno, es decir, a aprovechar la disponibilidad de un bien público, sin asumir ningún costo en su generación ${ }^{41}$. Como señala Pablo De Lora, la incorporación de elementos como este permiten superar el indeseable efecto de la explotación egoísta de la generosidad ajena ${ }^{42}$.

El principio de reciprocidad promueve un objetivo deseable, buscado y necesario: la promoción de la solidaridad para salvar vidas, esto se constituye como el bien jurídico superior que lo justifica, agregando una medida de equidad en el proceso. La donación de órganos actúa como un compromiso adquirido en términos morales que obliga a la reciprocidad, en término de colectividad, no es individual. Los órganos se donan a la sociedad, representada en la institución y no para nadie en concreto (salvo el caso de donación entre vivos).

\section{Otras razones importantes para el déficit en donaciones}

La mera regulación legal no ha sido suficiente para frenar la escasez de órganos. Las fórmulas ensayadas en el contexto del altruismo han buscado concientizar a las personas para que en vida decidan donar (en sistemas opt in), se abstengan de manifestar la voluntad de no donar (en los sistemas opt out) o no se opongan a la extracción de órganos de algún familiar en caso de requerir su consentimiento. La negativa familiar se erige como una valla hasta ahora inexpugnable: en 10 años, y mediando dos leyes, la tasa de rechazo familiar se ha mantenido prácticamente intacta, así como también los niveles de desinformación

\footnotetext{
40. RAWLS, John: A theory of justice. Harvard University Press, 1971. Pág. 510.

41. RIVERA, Eduardo. Ob. Cit. Pág. 71.

42. DE LORA, Pablo. Ob. Cit. Pág. 1020.
}

Revista de Ciencias Sociales - Número 66 (2015) - Universidad de Valparáíso - ISSN 0716-7725-Valparáiso, Chile 
acerca del marco regulatorio vigente ${ }^{43}$. Sin embargo, las tasas de negativa familiar son similares a las de España o, sin ir más lejos, a las de Argentina, y ambos países ostentan cifras mejores a las chilenas pues han enfrentado el problema de la coordinación e infraestructura de mejor manera. En Chile, más del 30\% de los cuerpos que sí podrían estar disponibles, se pierden por este motivo ${ }^{44}$.

Lo anterior se suma a la debilidad del sistema de procuramiento. Existe un universo de "potenciales donantes" que está conformado por alrededor de 2.000 personas ${ }^{45}$. De estos potenciales donantes el sistema médico actual sólo está detectando cerca de trescientos casos, de modo que se están perdiendo 1.700 casos sin que la red los detecte. De estos 300, tenemos que considerar otras pérdidas (además de la negativa familiar) como aquella que se configura con aquellas personas que en vida manifestaron su voluntad de donar pero que fallecen en centros médicos donde no hay profesionales capaces de determinar la muerte encefálica o donde no existían equipos para mantener su corazón latiendo. La debilidad de esta red no sólo se aprecia en estas cifras, sino además en su limitada extensión territorial, pues sólo funciona de Valparaíso a Valdivia y no en todos los hospitales que componen aquel tramo geográfico ${ }^{46}$.

43. Estudio Corpa (1999); Estudio Ipsos (2002, 2007), Estudio UDP (2010). En:

Departamento de Evaluación de la Ley. Cámara de Diputados de Chile: Evaluación Ley 20.413.

44. RIQUELME, Guillermo. Trasplantes: Los órganos que el sistema pierde y los chilenos que se niegan a donar. En: CIPER CHILE, 2010. Disponible en: http:/ /ciperchile.cl/2010/10/05/trasplantes-el-drama-de-los-que-esperan-los-organos-queel-sistema-pierde-y-la-no-donacion-de-otros/

45. De las 100 mil personas que mueren en Chile al año, sólo el $2 \%$ puede ser donante, pues el potencial donante debe haber sido declarado con "muerte encefálica”. Ídem.

46. RIQUELME, Guillermo. Ob. Cit.

Facultad de Derecho y Ciencias Sociales - Universidad de Valparaíso - Chile 


\section{Conclusiones}

La temática propuesta no constituye una cuestión ética y jurídica neutra, puesto que involucra complejas y difíciles decisiones morales, filosóficas, sociológicas, e incluso religiosas, que han suscitado agudas controversias en el contexto del debate y la discusión contemporánea. Una discusión, por cierto, del todo pertinente en sociedades como la nuestra, así como en la mayoría de los países desarrollados, en los cuales se considera que los trasplantes de órganos forman parte de aquella idea del "mínimo sanitario decente" ${ }^{47}$. De allí radica la importancia y el desafío para los Estados y sus sistemas sanitarios.

De los modelos ensayados en el derecho comparado, la evidencia disponible parece indicar que en razón al carácter del sistema, el de consentimiento presunto se consolida como el más eficaz, tanto así que la Organización Mundial de la Salud promueve su adopción en aquellos países en donde subsiste un modelo diverso ${ }^{48}$. La justicia distributiva valida las demandas de igualdad de oportunidades de los sujetos más débiles de la sociedad, entendiendo que todos los individuos tienen derecho a vivir una vida digna. La adopción del principio de reciprocidad, introducido a la legislación chilena con la Ley 20.673 es bienvenida y necesaria dada la condición de escasez de los recursos disponibles en materia de donación de órganos. Supone incorporar un requisito moral mínimo y plausible a la distribución de recursos sanitarios escasos, aportando además, equidad al sistema.

\section{Bibliografía}

BEECHER, Henry: "A Definition of Irreversible Coma. Report of the Ad Hoc Committee of the Harvard Medical School to Examine the Definition of Brain Death”. En: JAMA, Vol. 205, 1968.

47. ZÚNIGA-FAJURI, Alejandra. Equidad y derecho a la protección de la salud". Cuadernos de la Cátedra de Democracia y Derechos Humanos, Núm. 10. Universidad de Alcalá, Defensor del pueblo, 2013.

48. University of Nottingham. "Organ donation: Do we opt-in or opt-out?" En:

Science Daily. 24 September 2014. Disponible en: www.sciencedaily.com/ releases/2014/09/140924085129.htm 
BOWLES, Samuel, et al: "Group Competition, Reproductive Leveling, and the Evolution of Human Altruism". En: Science, Vol. 314, 2006.

CAPRON, Alexander: "More Blessed to give than to receive?". En: Trasplantation Proceedings, Vol. 24, 1992. Pp. 2185-2187.

CARDOSO, Cruz, CASAS, María de la Luz, RAMÍREZ, Hugo: "Los costos del altruismo en Donación de Órganos". En: Cuadernos de Bioética. Vol. 21, Nº 2, 2010.

CECCHETTO, Sergio. "La propiedad del cuerpo humano: consentimiento expreso y presunto en la donación de órganos".

En: Doctrina Promiscua; Mar del Plata; Serie Tesis; Ediciones Suárez, 2003.

CHARLESWORTH, Max: La bioética en una sociedad liberal. Cambridge University Press, 1996. P. 176.

CRONIN, Antonia: "Points mean prizes: priority points, preferential status and directed organ donation in Israel". En: Israel Journal of Health Policy Research, Vol. 3, 2014.

DE LORA, Pablo: "El trasplante de órganos y el caso del tranvía. ¿Por qué no confiscamos los órganos del cadáver?”. En: Jueces para la

Democracia. Información y debate, $\mathrm{N}^{\circ} 74,2012$, pp. 11-25.

FABRE, Cécile: Whose Body Is It Anyway? Justice and the integrity of the person, Oxford University Press, 2006.

GEVERS, Sjef, JANSSEN, Anke y FRIELE, Roland: "Consent systems for post mortem organ donation in Europe. En: EuropeanJournal of HealthLaw, 2004.

LEAVE, Jacob, ASHKENAZI, Tamar, GURMAN, Gabriel, STEINBERG, David: "A new law for allocation of donor organs in Israel”. En: Lancet, Vol. 375, No 9720, 2010.

MARTÍN, Antonio, MARTÍNEZ, José Manuel, LÓPEZ, Jorge: "La donación en España: un estudio sobre los aspectos psicosociales".

En: Coordinación y trasplantes. El modelo español. Madrid, Grupo Aula Médica S.A. 1995.

NADEL, Mark, NADEL, Carolina: "Using Reciprocity to Motivate Organ Donations". En: Yale Journal of Health Policy, Law, and

Ethics. Vol. 5: Issue 1, Article 5, 2005.

RAWLS, John: A theory of justice.Harvard University Press, 1971.

Facultad de Derecho y Ciencias Sociales - Universidad de Valparaíso - Chile 
RITHALIA, MCDAID, SUEKARRAN, MYERS and SOWDE: "A systematic review of presumed consent systems for deceased organ donation”. En: Health Technology Assessment, Vol. 13: № 26, 2009.

RIQUELME, Guillermo. Trasplantes: Los órganos que el sistema pierde y los chilenos que se niegan a donar. En: CIPER CHILE, 2010. Disponible en: http://ciperchile.cl/2010/10/05/trasplantes-el-drama-delos-que-esperan-los-organos-que-el-sistema-pierde-y-la-no-donacionde-otros/

RIVERA LÓPEZ, Eduardo. Ética y trasplante de órganos. Fondo de Cultura Económica, México, 2001.

RODRÍGUEZ ARIAS, David y CASADO, Antonio: "Controversias actuales sobre el consentimiento para la donación de órganos".

Ensayos sobre Bioética. Ediciones Universidad de Salamanca, octubre de 2009.

RODRÍGUEZ ARIAS, David y CASADO, Antonio: "El consentimiento para la donación de órganos: tipología”. Ensayos sobre Bioética.

Ediciones Universidad de Salamanca, I Edición, 2009.

RODRÍGUEZ, Jesús: "El igualitarismo liberal de John Rawls”. Estudio de la Teoría de la Justicia, Universidad Autónoma Metropolitana,

Iztapalapa, Miguel Ángel Porrúa, México, 2010, p. 240.

ZÚNIGA FAJURI, Alejandra. Equidad y derecho a la protección de la salud". Cuadernos de la Cátedra de Democracia y Derechos

Humanos, Núm. 10. Universidad de Alcalá y Defensor del pueblo, Madrid, 2013.

ZÚNIIGA FAJURI, Alejandra. "Increasing organ donation by presumed consent and allocation priority: Chile". Bulletin of the World

Health Organization, 2015; 93: pp. 199-202. 